\title{
CT-assisted stereotactic brain biopsy: value of intraoperative frozen section diagnosis
}

\author{
HAROLD J COLBASSANI,* SHUNJI NISHIO,† KEVIN M SWEENEY,* \\ ROY A E BAKAY,* YOSHIO TAKEI $\dagger$ \\ From the Departments of Pathology (Neuropathology) $\dagger$ and Surgery (Neurosurgery),* Emory University \\ School of Medicine, Atlanta, Georgia, USA
}

SUMMARY In 100 recent CT-guided brain biopsies, the value of intraoperative histologic examination using frozen section technique was evaluated. In 87 of these cases, the biopsy was performed stereotactically. In the remaining 13 cases, a CT-guided free hand technique was used. Of the 100 biopsies performed, adequate tissue for histopathologic diagnosis was obtained in 97, and in three the biopsy was nondiagnostic. In 61 procedures the initial biopsy specimen was adequate for diagnosis. Two specimens were required in 25 and in the remaining cases it was necessary to obtain three to four biopsy specimens before a definitive diagnosis could be made. Ultimately, the histologic diagnosis was made on frozen section examination in 93 of the cases. The lesions identified were neoplastic disease in 83 cases, vascular disease in seven, infectious disease in five, demyelinating disease in one, and radiation necrosis in one. Comparison between the frozen section diagnosis and the final diagnosis based on the permanent sections revealed that they matched in 89 cases $(92 \%)$. त) Of the 83 cases of neoplasms the exact grade of malignancy was determined by frozen section examination in $71(85 \%)$. Comparison between the size of tissue samples obtained and the ability to make a final diagnosis revealed that even if the specimen volume was less than $2 \mathrm{~mm}^{3}$, the biopsy was generally successful. The disadvantages of the small sample size obtained through needle biopsy are best overcome by careful targeting and assessment of sample quality by intraoperative frozen? section examinations, which will give the definitive diagnosis in most of the cases without paraffin-embedded sections.

Despite the high resolution of computed tomography (CT), and magnetic resonance imaging (MRI), the specificity of these modalities remains limited. ${ }^{1-6}$ Therefore, therapeutic decisions must be based upon an unequivocal histological diagnosis.

In 1947 Spiegel et al first introduced the use of stereotactic techniques in obtaining biopsy material from human subcortical structures. ${ }^{7}$ Today, these basic principles remain the same; however, the combination of stereotactic techniques and computed tomography has made biopsy of even minute lesions

Address for reprint requests: Yoshio Takei, MD, Division of Neuropathology, Emory University Hospital, 1364 Clifton Road, N.E. Atlanta, Georgia 30322, USA.

Received 16 March 1987 and in revised form 3 June 1987 Accepted 14 July 1987 in highly functional areas both safe and reliable. ${ }^{8-15}$

While stereotactic biopsy increases the accuracy of obtaining appropriate tissue for precise diagnosis, specimens obtained by the initial needle passage are sometimes insufficient for a definitive histologic interpretation. Microscopical examination of such specimens provides the ability to determine the necessity of additional needle passages. Thus, rapid, intraoperative histological examination of each biopsy sample by a well-trained neuropathologist will provide complete and reliable information on a minimum amount of tissue and avoid the risk of further biopsy. We review our experience on 100 brain biopsies, in which a CT-guided needle biopsy and intraoperative frozen section examination was performed for diagnosis of a variety of pathological entities. The value of intraoperative frozen section diagnosis in CT-guided brain biopsy is evaluated. 
Table 1 Location of biopsied lesions $(N=97)$

\begin{tabular}{lrr}
\hline Supratentorial & \multicolumn{2}{c}{86} \\
Cerebral hemisphere & 39 & \\
$\quad$ Left & 15 & \\
Right & 5 & \\
Corpus callosum & 4 & \\
Basal ganglia & 16 & \\
Thalamus, hypothalamus & 1 & \\
Pineal region & 2 & \\
Ventricle & 4 & \\
$\quad$ Lateral & & \\
Third & \multicolumn{2}{c}{11} \\
& 3 & \\
Infratentorial & 6 & \\
Midbrain & 2 & \\
Pons/medulla & \multicolumn{2}{c}{97} \\
Cerebellum & & \\
Total &
\end{tabular}

\section{Patients and methods}

During the period April 1983 to June 1986, 100 CT-guided needle biopsies of brain lesions were performed on 98 patients at Emory University Hospital. In 87 cases, biopsies were performed with CT guidance (General Electric $\mathbf{8 8 0 0}$ scanner), using the multiplanar stereotactic head frame (Howland Industries, Stanton, California) and software to produce simultaneous axial, coronal, and sagittal reconstructions, allowing a three-dimensional assessment of the target tissue. ${ }^{9}$ In the remaining 13 cases the biopsy was performed by a free hand technique. The biopsy procedure was generally carried out under local anaesthesia, except in children younger than 12 years. The patients included 53 males and 44 females, aged from 1 to 89 years (mean $37 \cdot 5)$. The anatomical origin of the specimens is given in table 1 .

Specimens were obtained with an 18-gauge guillotine needle, usually from the periphery or contrast enhancing edge (if present), and the centre of the lesion shown on CT scan. Specimens were placed on a flat piece of rubber glove and then wrapped in a towel to keep them moist. The specimens were examined immediately by the pathologists and the approximate volume of the sample was evaluated in many cases. Frequently, a small sample was taken for electron microscopy, and then the remainder of the specimen was frozen and sectioned in a cryostat (American Optical Cryostat, Buffalo, NY), which was kept at $-20^{\circ} \mathrm{C}$. A small mount comprising of embedding medium for frozen sections was prepared on a chuck inside the cryostat and then frozen with the aid of a commercially available freon spray. After freezing, sections were cut at 3 or $4 \mu \mathrm{m}$ thickness. The slides were then stained with haematoxylin and eosin, and toluidine blue $(0.7 \%$ solution). The frozen specimens were subsequently fixed in $10 \%$ formalin solution and were processed through a routine paraffin embedding technique. The histopathological findings of the frozen section, and paraffin-embedded sections were interpreted by the senior author (YT) in each case. Depending on the frozen section diagnosis and CT findings, one or more tissue samples were usually then taken, until frozen section diagnosis was established. In some cases it was decided to wait for paraffin-embedded sections rather than subject the patient to the additional risk of further biopsy.
Table 2 Final diagnosis of biopsied lesions $(N=97)$

\begin{tabular}{|c|c|c|}
\hline \multicolumn{3}{|l|}{$\begin{array}{l}\text { Neoplastic lesion } \\
\text { Astrocytoma }\end{array}$} \\
\hline Fibrillary & 18 & \\
\hline Protoplasmic & 9 & \\
\hline Gemistocytic & 2 & \\
\hline Malignant & 23 & \\
\hline Glioblastoma multiforme & 7 & \\
\hline Other gliomas* & 4 & \\
\hline Neuroblastoma & 2 & \\
\hline Malignant lymphoma & 2 & \\
\hline Other primary brain tumourt & 5 & \\
\hline Metastatic tumour & 11 & \\
\hline Vascular lesion & & 7 \\
\hline Haematoma & 2 & \\
\hline $\begin{array}{l}\text { Infarction } \\
\text { Infertious }\end{array}$ & 5 & \\
\hline $\begin{array}{l}\text { Infectious lesion } \\
\text { Others } \neq\end{array}$ & & 0 \\
\hline Total & & 9 \\
\hline
\end{tabular}

*Ependymoma (1); choroid plexus papilloma (1);

oligodendroglioma (1); subependymoma (1).

†Hamartoma (1); germinoma (1); craniopharyngioma (1); neuroepithelial cyst (1); pineoblastoma (1).

$\ddagger$ Multiple sclerosis (1); radiation necrosis (1).

The final pathological diagnosis was the result of rapid intraoperative frozen section examination, histological examination of paraffin-embedded materials, and sometimes electron microscopic or immunocytochemical examinations. This diagnosis was compared with the clinical impression and frozen section diagnosis in each case. Special attention was paid to any discrepancies and these were reviewed in conjunction with an assessment of sample volume and type of lesions.

\section{Results}

After combined CT-guided biopsy and intraoperative frozen section examinations, an adequate sample for histological confirmation of lesion type was obtained in 97 of the 100 biopsies. In the three nondiagnostic

Table 3 Correlation of clinical impression with final histopathological diagnosis $(N=97)$

\begin{tabular}{lll}
\hline & \multicolumn{2}{l}{$\begin{array}{l}\text { Agreement with final } \\
\text { histopathological diagnosis? }\end{array}$} \\
\cline { 2 - 3 } Clinical diagnosis & Yes & No \\
\hline Primary brain tumour & 60 & $9^{*}$ \\
Primary vs metastatic tumour & 7 & 0 \\
Primary tumour vs radiation & 3 & 0 \\
$\quad$ necrosis & 7 & 0 \\
Tumour vs infectious lesion & 4 & 0 \\
Tumour vs infarction & 2 & 0 \\
Otherst & 4 & $1 \ddagger$ \\
\hline
\end{tabular}

*Included is a case in which the clinical diagnosis of "brain tumour of glial origin" was identified histologically as "organising haematoma". This was subsequently confirmed by the patients' clinical course.

†Haematoma (1); abscess vs infarction (1); multiple sclerosis (2); encephalitis (1).

IIn this case a clinical diagnosis of "multiple sclerosis" was identified histologically as "gemistocytic astrocytoma arising in a demyelinating focus". 


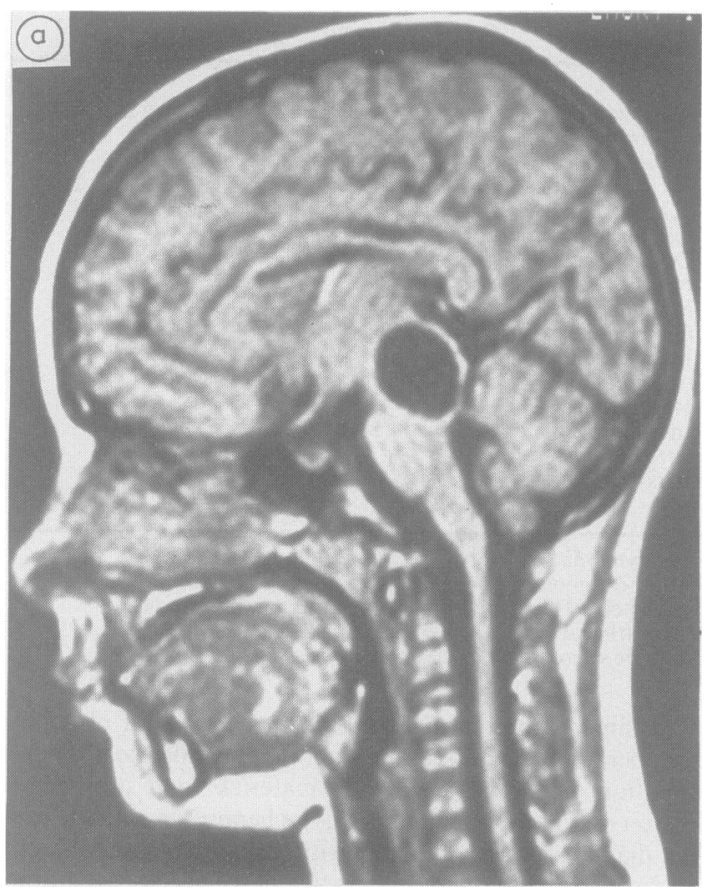

biopsies, the procedure was terminated before an adequate tissue sample for confirmation of lesion type was obtained. However, these three biopsies were performed early in our series and it was thought additional biopsy would expose the patient to an unacceptable risk. Subsequently, a more aggressive approach in obtaining tissue for a definitive diagnosis has been adopted without increased morbidity. Analyses mainly on the 97 biopsies, in which a definitive histological diagnosis was obtained, are described below.

\section{General aspects}

The diagnoses based upon the histological findings are presented in table 2 . The majority of the lesions in this series were tumours of the glioma group $(\mathrm{N}=63)$, with the malignant astrocytoma being the most frequent $(\mathbf{N}=23)$. An ependymoma, oligodendroglioma, subependymoma and choroid plexus papilloma were each encountered once. Metastatic tumours were less frequent and were identified in 11 cases. Two neuroblastomas, corroborated by ultrastructural examination, and two malignant lymphomas, corroborated by immunocytochemical studies were also seen. Rarely encountered were craniopharyngioma, germinoma,
Fig 1 (A) MRI scan of a cystic lesion of the midbrain in a 12 year old boy. TE $30 \mathrm{~ms}$, TR $540 \mathrm{~ms}$. Based upon the clinical impression and radiographic findings, a working diagnosis of a brainstem glioma was made. (B) CT scan obtained at the time of stereotactic biopsy. The axial image as well as reconstructed coronal and sagittal images are seen. The simulated trajectory between entrance and target points is also depicted. (C) Biopsy specimen examined by frozen section demonstrating a neuroepithelial cyst. This tissue was lost in the paraffin-embedded materials. Hematoxylin and Eosin, $\times 200$. neuroepithelial cyst of the midbrain, and pineoblastoma

2 Correlation of clinical impression to final histopathological diagnosis (table 3 )

A clinical impression of a primary brain tumour was confirmed histologically in 60 cases. In eight cases histological examination altered the clinical diagnosis as to the tumour type. This included four metastatic tumours, which were diagnosed clinically as malignant astrocytoma in three cases and glioblastoma multiforme in one case. Two neuroblastomas and one lymphoma were diagnosed clinically as malignant astrocytomas; and one neuroepithelial cyst was initially diagnosed as a low grade astrocytoma (fig 1). In one other case the diagnosis had to be changed to "organising haematoma" which, clinically, was suspected to be a brain tumour of glial origin. Organising haematoma as a definitive diagnosis without evidence of neoplastic growth was confirmed by serial CT scans and the subsequent clinical course of this patient. A clinical impression of "primary vs secondary tumour" was found to be a primary brain tumour in all seven cases. A clinical impression of "tumour vs radiation necrosis" was found to be tumour in two and radiation necrosis in one. Seven cases with a suspected diagnosis of "tumour vs infectious lesion" were found to be tumour in four and infection in the remaining three cases. 


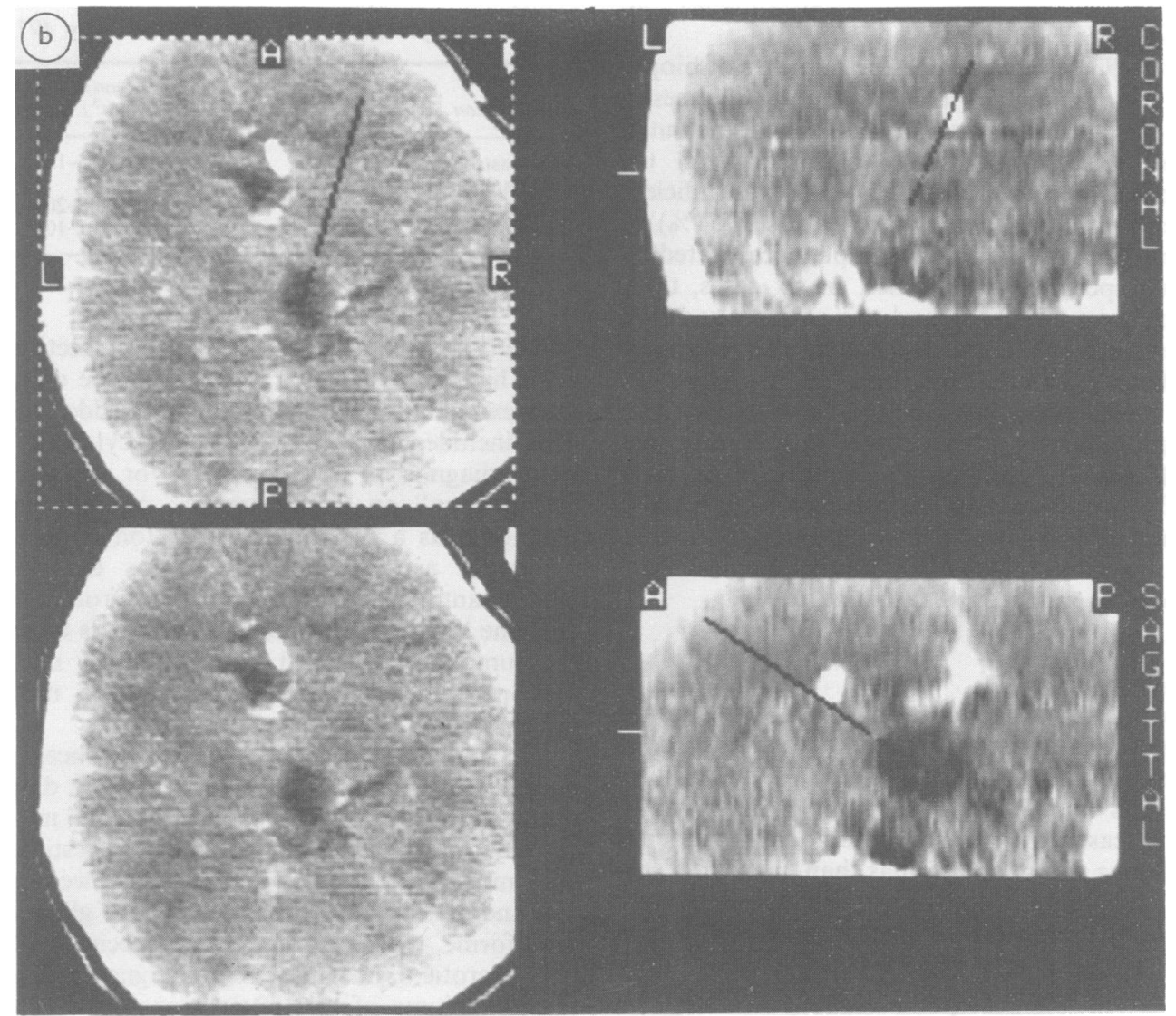

(c)

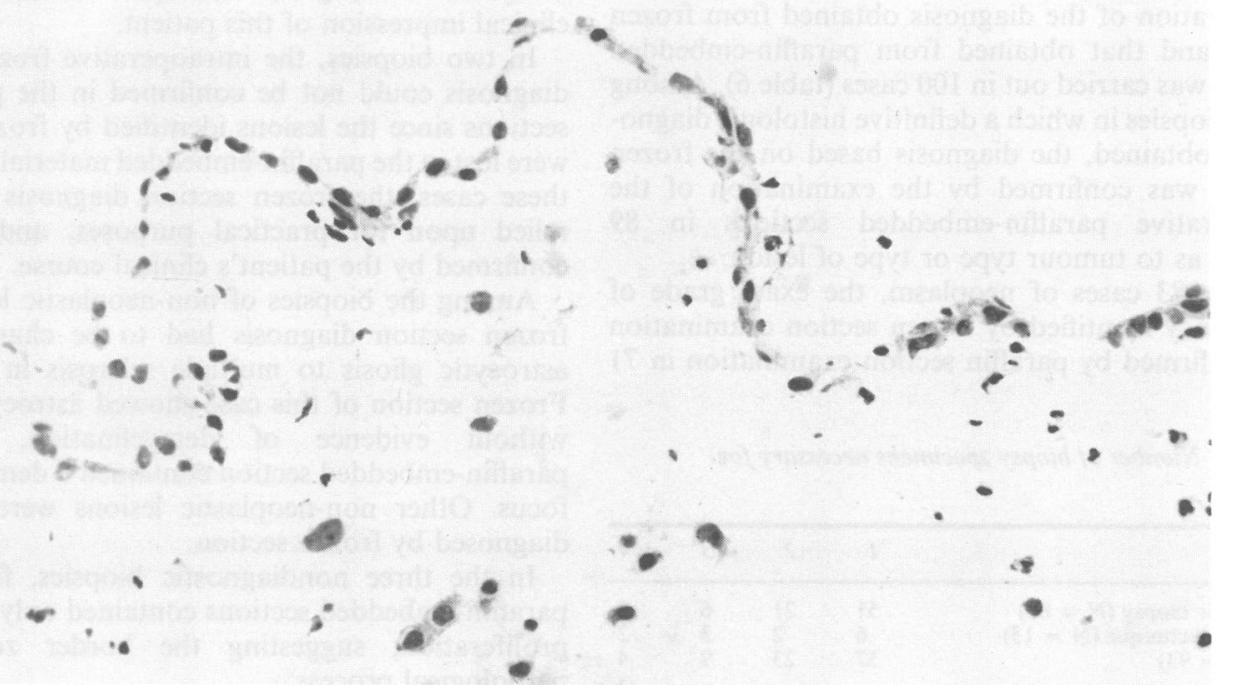




\section{Number of tissue samples}

There were 93 cases, in which the numbers of biopsy samples were evaluable (table 4). Among 80 cases in which a stereotactic biopsy was performed, the initial specimen, which was usually obtained from the periphery of the lesion delineated on CT was sufficient for exact histological diagnosis in 51 cases $(64 \%)$. A negative report on the initial sample necessitated an additional specimen in 21 cases. In six cases, three specimens were necessary, and two patients had four or more specimens taken before obtaining an appropriate biopsy sample for histological diagnosis. Among the 13 cases, in which free hand biopsy with CT guidance was performed, the initial specimens were sufficient for histological diagnosis in six cases $(46 \%)$. In two cases, two specimens were necessary, three patients had three specimens, and two patients had four specimens taken before a histological diagnosis could be made.

\section{Volume of sample}

The volume of sample, from which a definitive histological diagnosis was obtained, was evaluable in 71 biopsies. In 48 biopsies (67\%) the volume of sample was less than $2 \mathrm{~mm}^{3}$. The sample tended to be bigger in cases of metastatic tumours, malignant astrocytomas and glioblastomas than in those of low grade astrocytomas. However, there was no definite correlation between the volume of samples and type of lesion (table 5). The total sample volumes of the three cases in which the biopsy was nondiagnostic, ranged from 4 to $17 \mathrm{~mm}^{3}$.

5 Accuracy of intraoperative frozen section diagnosis A correlation of the diagnosis obtained from frozen section and that obtained from paraffin-embedded sections was carried out in 100 cases (table 6). Among the 97 biopsies in which a definitive histologic diagnosis was obtained, the diagnosis based on the frozen sections was confirmed by the examination of the postoperative paraffin-embedded sections in 89 biopsies as to tumour type or type of lesion.

In the 83 cases of neoplasm, the exact grade of malignancy identified by frozen section examination was confirmed by paraffin section examination in 71

Table 4 Number of biopsy specimens necessary for diagnosis

\begin{tabular}{lrrrr}
\hline & 1 & 2 & 3 & 4 \\
\hline Stereotactic biopsy $(\mathrm{N}=80)$ & 51 & 21 & 6 & 2 \\
Free hand technique $(\mathrm{N}=13)$ & 6 & 2 & 3 & 2 \\
Total $(\mathrm{N}=93)$ & 57 & 23 & 9 & 4 \\
\hline
\end{tabular}

Table 5 Sample volume and type of lesion $(N=49)$

\begin{tabular}{ll}
\hline Type of lesion & $\begin{array}{l}\text { Mean sample volume } \\
\left(\mathrm{mm}^{3}\right)(\text { range })\end{array}$ \\
\hline $\begin{array}{l}\text { Benign astrocytoma }(\mathrm{N}=19) \\
\begin{array}{l}\text { Malignant astrocytoma/glioblastoma } \\
\text { multiforme }(\mathrm{N}=23)\end{array}\end{array}$ & $2 \cdot 3(0 \cdot 5-12)$ \\
\begin{tabular}{l} 
Metastatic tumour $(\mathrm{N}=7)$ \\
\hline
\end{tabular} & $3 \cdot 7(0 \cdot 5-20)$ \\
\hline
\end{tabular}

(85\%) (fig 2). In seven cases, the frozen section diagnosis had to be changed in tumour type or grading after examination of the paraffin-embedded sections. This included four malignant astrocytomas, which were diagnosed as "fibrillary or protoplasmic astrocytoma" on frozen section; one glioblastoma diagnosed as a malignant astrocytoma (fig 3); one malignant astrocytoma, which was diagnosed as "malignant neuroglial tumour" on frozen section; and one "malignant tumour" (no details concerning the tumour type could be determined on frozen section), which had to be changed to metastatic carcinoma.

A diagnostic error in frozen sections concerning the $\vec{\sigma}$ presence of tumour tissue (false-negative diagnosis) occurred in three cases. This included one malignant astrocytoma, in which the specimen was estimated as $5.5 \mathrm{~mm}^{3}$ in total sample volume and showed only gliosis and oedema on frozen section; one glioblastoma multiforme, whose frozen section specimen revealed only necrotic tissue and was nondiagnostic. The total sample volume of this latter biopsy was estimated as $6.5 \mathrm{~mm}^{3}$. Lastly was a case of a gemistocytic astrocytoma arising in a demyelinating focus, in which the frozen section showed only the evidence of demyelination (fig 4). Multiple sclerosis was the clinical impression of this patient.

In two biopsies, the intraoperative frozen section diagnosis could not be confirmed in the permanent sections since the lesions identified by frozen section were lost in the paraffin-embedded materials (fig 1). In these cases, the frozen section diagnosis had been relied upon for practical purposes, and this was confirmed by the patient's clinical course.

Among the biopsies of non-neoplastic lesions, the frozen section diagnosis had to be changed from astrocytic gliosis to multiple sclerosis in one case. Frozen section of this case showed astrocytic gliosis without evidence of demyelination, but the paraffin-embedded section contained a demyelinating focus. Other non-neoplastic lesions were correctly diagnosed by frozen section.

In the three nondiagnostic biopsies, frozen and paraffin-embedded sections contained only astrocytic proliferation, suggesting the border zone of a pathological process. 

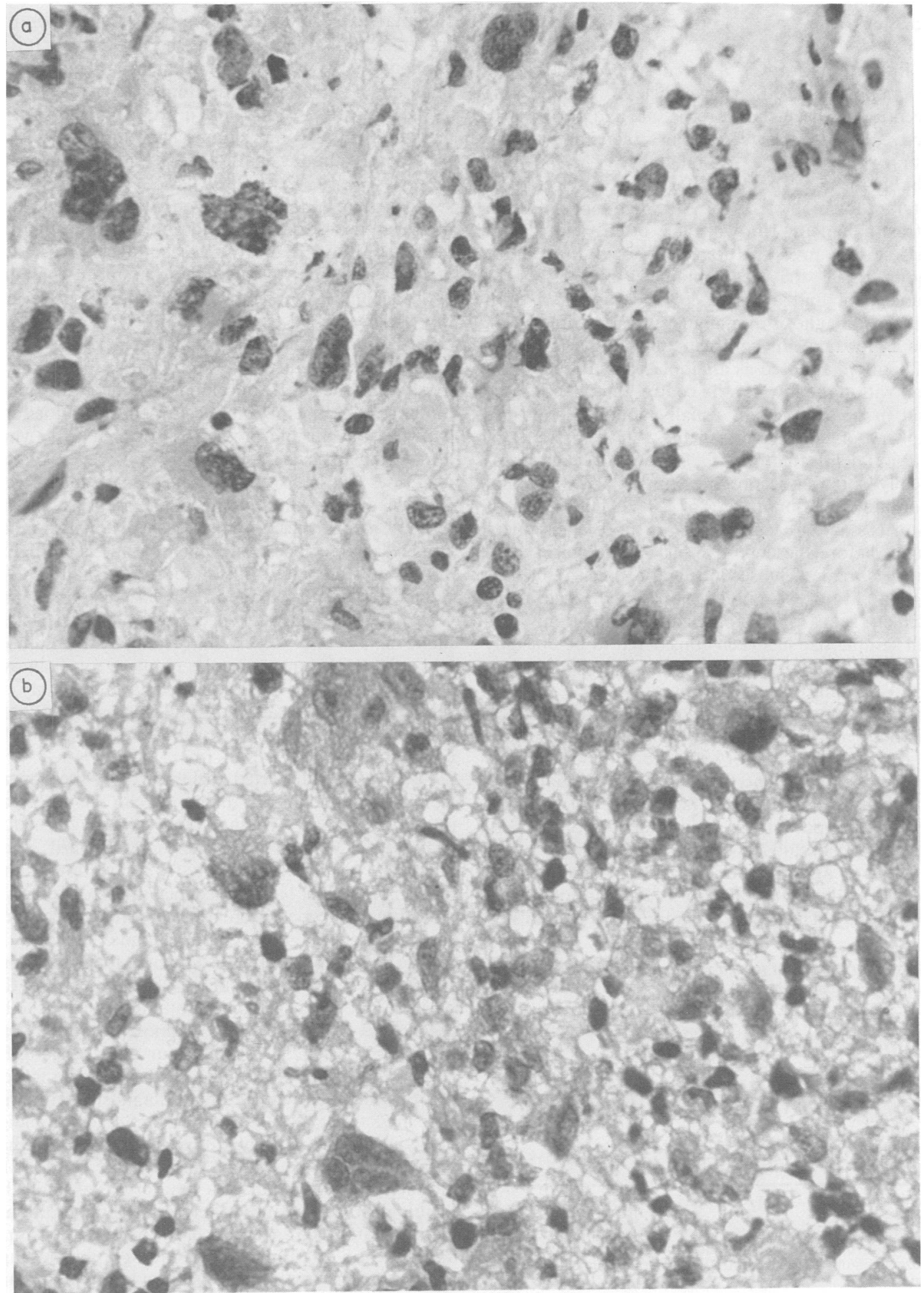

Fig 2 Biopsy specimen of a malignant astrocytoma, in which frozen and paraffin-embedded sections were in agreement. Numerous pleomorphic and multinucleate forms can be seen. (a) Frozen section.

(b) Permanent section. Hematoxylin and Eosin $\times 900$. 


\section{Discussion}

The indications for CT assisted stereotactic biopsy are well-established. Nevertheless, while this procedure has been shown to be safe and particularly effective for deep-seated lesions, there are several factors which influence its reliability. The first and probably the most important factor is the selection of the target for biopsy. ${ }^{\mathbf{1 0 - 1 8}}$ Although biopsy from a contrast-enhancing rim will most often yield a diagnosis, several investigators have noted that viable tumour tissue may be obtained from areas of enhancement and areas of low density. ${ }^{10-1216}$ In addition, a diagnosis of malignant astrocytoma based upon a biopsy of the contrast-enhancing rim may be confidently diagnosed as a glioblastoma if necrosis is found within the low density centre. In our series, the initial tissue sample was usually obtained from the periphery or contrast-enhancing rim (if present) of the lesion delineated on CT. This was checked histologically by frozen section preparation and was found to contain the lesion in $61 \%$ of cases. Thus, in $39 \%$ it was necessary to take two or more subsequent samples before the definitive histopathological diagnosis was made. The second factor which influences the reliability of CT-guided biopsy is the size of the specimen sent for histological examination. This small sample size has been considered to be not only the essential limitation in making a diagnosis but also the most common cause of misdiagnosis. ${ }^{19}$ As demonstrated in our series, however, the accuracy of diagnosis does not always increase proportionately with the size of the specimen. A sample volume of $2 \mathrm{~mm}^{3}$ proved to be sufficient for diagnostic evaluation in $67 \%$ of cases. Clearly, these factors are not mutually exclusive. The pathologist is dependent upon the neurosurgeon to obtain an optimal specimen for histological study and the neurosurgeon must rely on the expertise of the pathologist to inform him of a diagnostic biopsy. Thus, the combination of CT-assisted

Table 6 Correlation of frozen section diagnosis with paraffin embedded sections $(N=97)$

\begin{tabular}{llc}
\hline Type of lesion & $\begin{array}{l}\text { Positive } \\
\text { correlation* }\end{array}$ & $\begin{array}{l}\text { Negative } \\
\text { correlation }\end{array}$ \\
\hline $\begin{array}{l}\text { Neoplastic }(\mathrm{N}=83) \\
\text { Presence of tumour }\end{array}$ & 78 & $5 \dagger$ \\
Type of tumour & 76 & 7 \\
$\begin{array}{l}\text { Grade of malignancy } \\
\text { Non-neoplastic (N = 14) }\end{array}$ & 71 & 12 \\
Type of lesion & 13 & 1 \\
\hline
\end{tabular}

*Frozen section diagnosis was confirmed by paraffin embedded sections.

tIncluded are two cases, in which tumour was present only in the frozen section, and three cases in which tumour was not present in the frozen section but was identified in the paraffin embedded sections. stereotactic technique and precise intraoperative $\frac{}{Z}$ frozen section diagnosis has been most useful in $\mathbb{D}$ eliminating the undesirable (that is, nondiagnostic) outcome of the biopsy procedure.

As a means of making a rapid intraoperative $\stackrel{\bar{\theta}}{c}$ diagnosis, smear preparations have long been used, $D$ particularly among pathologists of the European school. ${ }^{1519-26}$ Eisenhardt and Cushing ${ }^{22}$ and subsequently Badt ${ }^{20}$ were among its early advocates; however, its use became widespread only after the introduction of the wet film technique by Russell et $a l .^{26}$ The principal advantages of the smear technique $\bar{\sigma}$ are its technical simplicity, the ease with which several tiny fragments of tissue can be screened, and the clarity of detail. Smear preparations, however, often destroy tissue architecture, and are variable in thickness so that the degree of cellularity may be difficult to evaluate. McMenemey emphasised the difficulties and dangers of misinterpretations particularly when attempting to grade astrocytomas; as only $66 \%$ of diagnoses based on smear preparations were $\overline{\bar{z}}$ confirmed by paraffin-embedded sections in his series. $^{23}$ More recent reports have shown a much or higher degree of accuracy which in part is related tow improved stereotactic techniques. Marshall et $a l^{20} \underset{\omega}{\omega}$

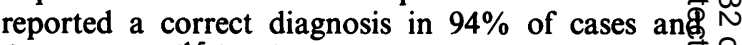
Ostertag et $\boldsymbol{l}^{15}$ has had success with the smear techp nique in $95 \%$ of his cases. Unfortunately, the number and volume of biopsy samples required for diagnosis were not specified in these articles. Interestingly, i the report by Ostertag et al, a diagnosis based upo paraffin-embedded sections was not possible in $31 \%$ of the cases. ${ }^{15}$

Despite the reported accuracy of the smear technique, a definitive diagnosis can be obtained intraoperatively utilising the frozen section technique. ${ }^{11131427}$ In the series by Bullard et al, diagnosis was established on frozen section examination of the first biopsy specimen in $65 \%$ of cases. ${ }^{11}$ Additional specimens were necessary in the remaining cases before a diagnosis could be made. However, in approximately $50 \%$ of cases in which the first biopsy sample was non-diagnostic on frozen section, the paraffin-embedded section examinations proved to be diagnostic. Ultimately, a diagnostic biopsy was obtained in 49 of 50 cases. In our series, among 83 neoplasms, histological diagnoses based upon frozen sections matched with the final diagnosis in tumour type in 78 cases $(94 \%)$, and the exact grade of malignancy in $71(85 \%)$. It should be noted, however, that in neurosurgical pathology, one must be cautious in grading the malignancy of a tumour based upon the histological appearance of limited samples alone. Clinical data, such as the age of the patient, the tempo and duration of symptoms, the radiographic findings and the precise anatomical location of the lesion are 


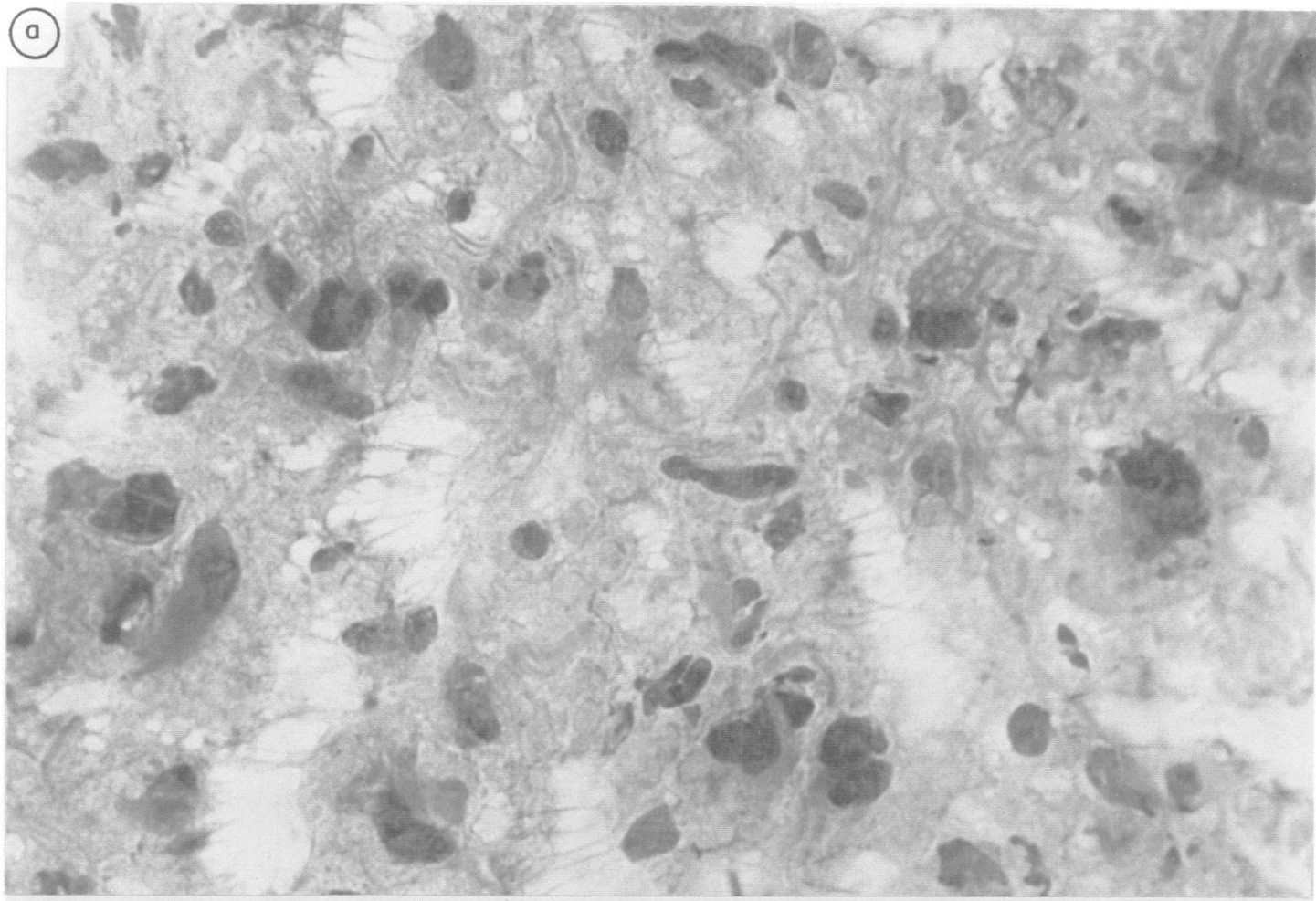

(b)

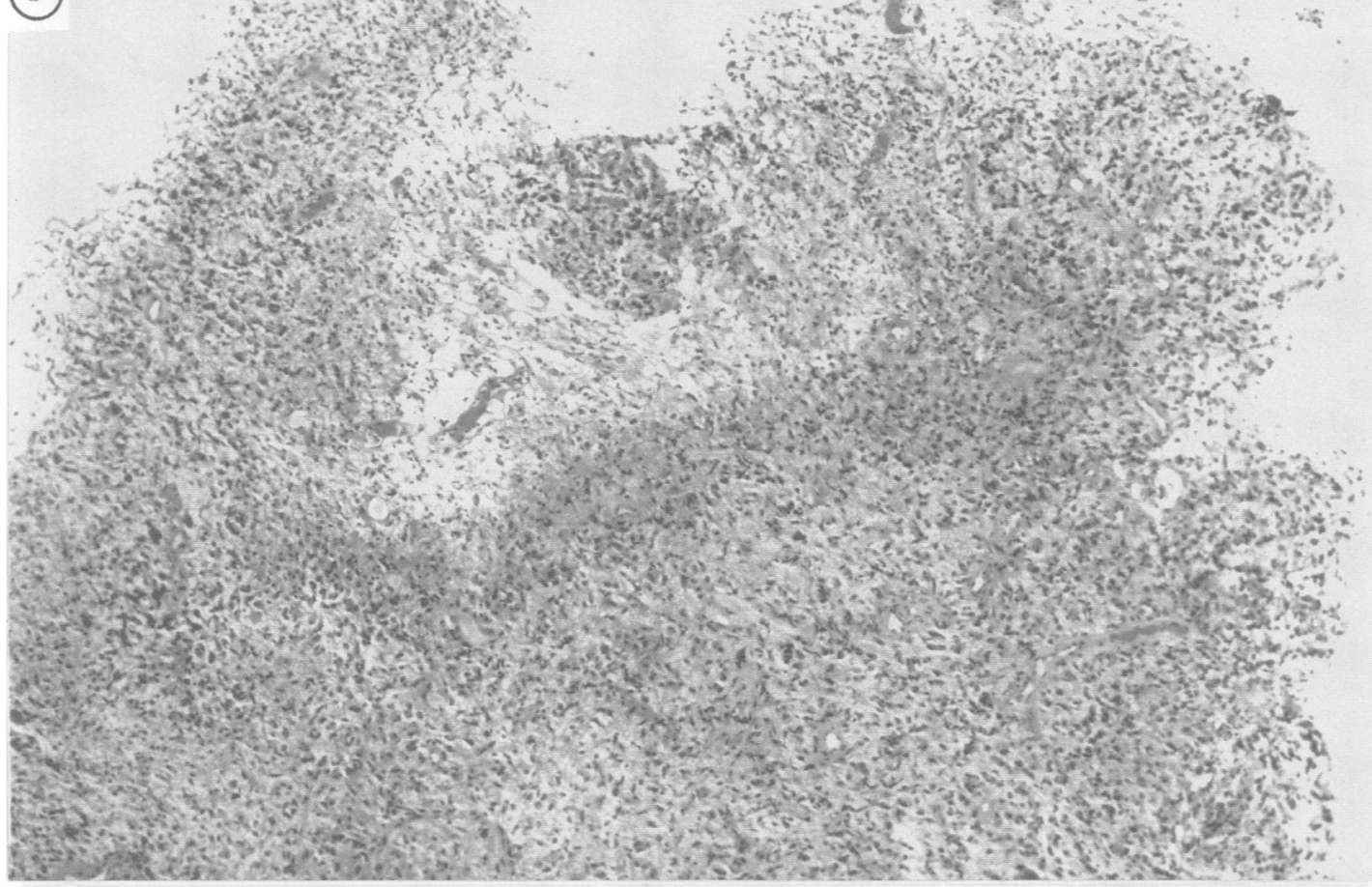

Fig 3 Biopsy specimen in which there was disagreement between frozen and paraffin-embedded sections as to tumour grade. (a) Frozen section depicting features of a malignant astrocytoma. Hematoxylin and Eosin $\times 900$. (b) Permanent section demonstrating a zone of necrosis and surrounding pseudopallisading, making the diagnosis of a glioblastoma multiforme more appropriate. Hematoxylin and Eosin $\times 60$. 

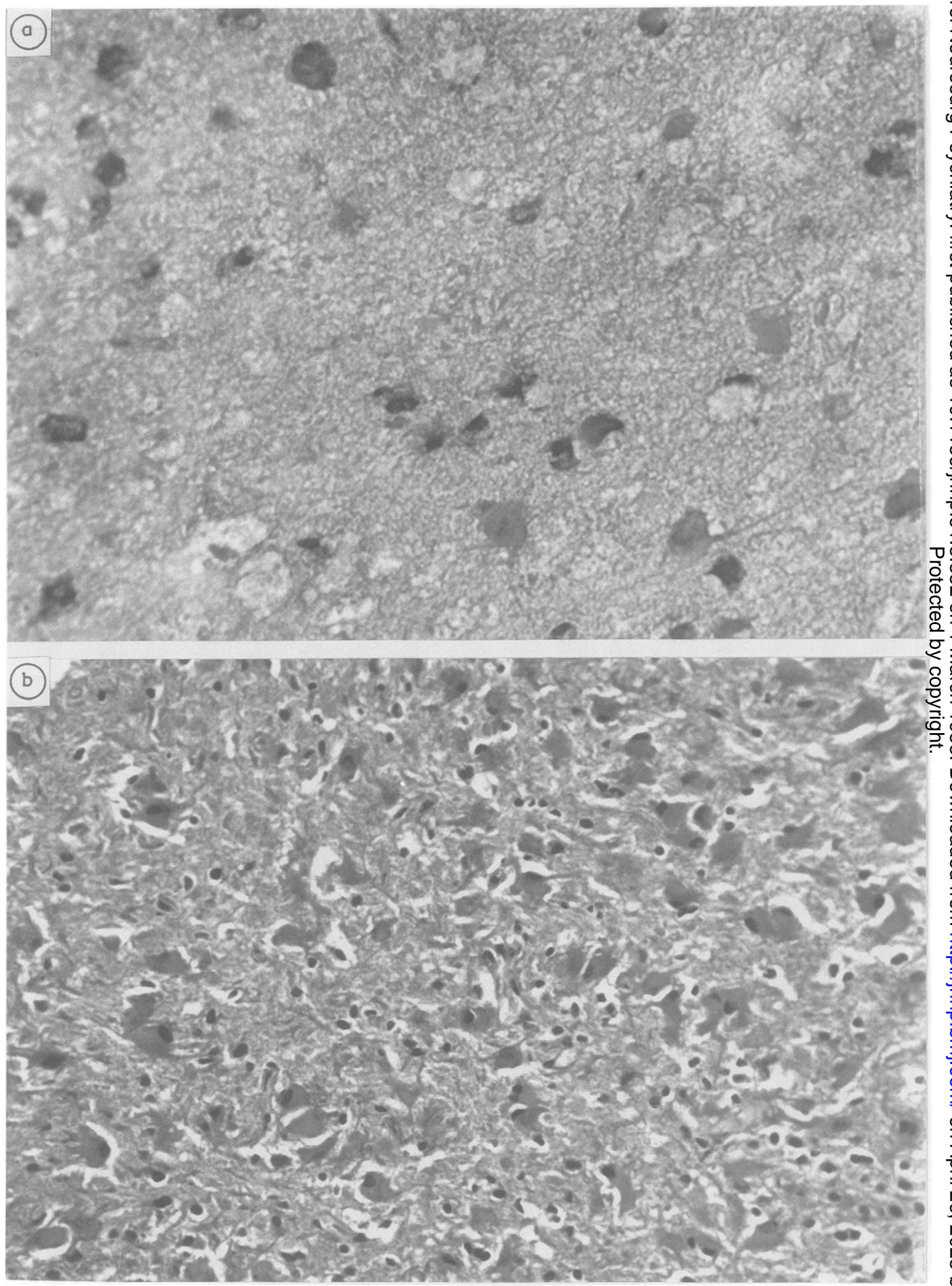

Fig 4 Biopsy specimen in which a false negative diagnosis was made on frozen section. (a) Frozen section depicting a focus of demyelination. Hematoxylin and Eosin $\times 900$. (b) Paraffin embedded section from the same tissue block which revealed a small focus of a gemistocytic astrocytoma arising within a demyelinating plaque. Luxol Fast Blue $\times 450$. 
very important in considering the grade of malignancy. In this respect, the pathologist must be familiar with the clinical spectrum of neurological disease and must be aware of the fact that a knowledge of CT-histology correlations by the neurosurgeon may enhance the value of the biopsy procedure.

Although frozen section preparations have been accused of frequently obscuring the fine cellular detail, ${ }^{21}$ an accurate judgement of the type of lesion and often the grade of malignancy can generally be made on frozen section examination alone. It is clear, however, that the combination of CT-guided stereotactic techniques and the meticulous application of the frozen section technique is responsible for this high degree of accuracy.

\section{References}

1 Araki $T$, Inouye $T$, Suzuki $H$, Machida $T$, lio $M$. Magnetic resonance imaging of brain tumors: Measurement of $\mathrm{T} 1$. Radiology 1984;150:95-8.

2 Brant-Zawadzki M, Badami JP, Mills CM, Norman D, Newton TH. Preliminary intracranial imaging: a comparison of magnetic resonance and CT. Radiology 1984;150:435-40.

3 Kendall BE, Jakubowski J, Pullicino P, Symon L. Difficulties in diagnosis of supratentorial gliomas by CAT scan. J Neurol Neurosurg Psychiatry 1979;42:485-92.

4 Latchaw RE, Gold LHA, Moore JS Jr, Payne JT. The nonspecificity of absorption coefficients in the differentiation of solid tumors and cystic lesions. Radiology 1977;125:141-4.

5 Latchaw RE, Payne JT, Loewenson RB. Predicting brain tumor histology: change of effective atomic number with contrast enhancement. AJNR 1980;1:289-94.

6 Lee BCP, Kneeland JB, Cahill PT, Deck MDF. MR recognition of supratentorial tumors. AJNR 1985;6:871-8.

7 Spiegel EA, Wycis HT, Marks M, Lee AJ. Stereotaxic apparatus for operations on human brain. Science 1947;106:349-50.

8 Apuzzo MLJ, Sabshin JK. Computed tomographic guidance stereotaxis in the management of intracranial mass lesions. Neurosurgery 1983;12:277-85.

9 Bakay RAE, Hoffman JC, Rhodes M. Advantages of computerized tomography-assisted interaction during stereotactic procedures using computer-generated graphics. Appl Neurophysiol 1985;48:79-80.

10 Boethius J, Collins VP, Edner G, Lewander R, Zajicek J. Stereotactic biopsies and computer tomography in gliomas. Acta Neurochir 1978;40:223-32.
11 Bullard DE, Osborne D, Burger PC, Nashold BS Jr. Further experience utilizing the Gildenberg technique for computed tomography-guided stereotactic biopsies. Neurosurgery 1986;19:386-91.

12 Gildenberg PL, Kaufman HH, Murthy KSK. Calculation of stereotactic coordinates from the computed tomographic scan. Neurosurgery 1982;10:580-6.

13 Heilbrun MP, Roberts TS, Apuzzo MLJ, Wells TH, Sabshin JK. Preliminary experience with Brown-Roberts-Wells (BRW) computerized tomography stereotaxic guidance system. $J$ Neurosurg 1983;59:217-22.

14 Kelly PJ, Earnest F IV, Kall BA, Goerss SJ, Scheithauer B. Surgical options for patients with deep-seated brain tumors: computer-assisted stereotactic biopsy. Mayo Clin Proc 1985;60:223-9.

15 Ostertag CB, Mennel HD, Kiessling M. Stereotactic biopsy of brain tumors. Surg Neurol 1980;14:275-83.

16 Daumas-Duport C, Monsaingeon V, N'Guyen JP, Missir O, Szikla G. Some correlations between histological and CT aspects of cerebral gliomas contributing to the choice of significant trajectories for stereotactic biopsies. Acta Neurochir [Suppl] 1984;33:185-94.

17 Hitchon PW, Schelper RL, Barloon T. Accuracy of CT scans in identifying tumor tissue. Appl Neurophysiol 1985;48:463-6.

18 Scerrati M, Rossi GF. The reliability of stereotactic biopsy. Acta Neurochir [Suppl] 1984;33:201-5.

19 Kleihues P, Volk B, Anagnostopoulos J, Kiessling M. Morphologic evaluation of stereotactic brain tumour biopsies. Acta Neurochir [Suppl] 1984;33:171-81.

20 Badt B. Mikroskopische Schnelldiagnose bei hirnchirurgischen Eingriffen. Zbl Neurochir 1937;2:123-39.

21 Burger PC. Use of cytological preparations in the frozen section diagnosis of central nervous system neoplasia. Am J Surg Pathol 1985;9:344-54.

22 Eisenhardt $L$, Cushing $H$. Diagnosis of intracranial tumors by supravital technique. Am J Pathol 1930;6:541-52.

23 McMenemey WH. An appraisal of smear-diagnosis in neurosurgery. Am J Clin Pathol 1960;33:471-9.

24 Marshall LF; Adams H, Doyle D, Graham DI. The histological accuracy of the smear technique for neurosurgical biopsies. $J$ Neurosurg 1973;39:82-8.

25 Morris AA. The use of the smear technique in the rapid histological diagnosis of tumors of the central nervous system: description of a new staining method. J Neurosurg 1947;4:497-504.

26 Russell DS, Krayenbuhl H, Cairns $\mathbf{H}$. The wet film technique in the histological diagnosis of intracranial tumours; a rapid method. J Path Bact 1937;45:501-5.

27 Takei Y. Pathology of pituitary tumors and value of frozen section diagnosis. In: Tindall GT, Collins WF, eds. Clinical Management of Pituitary Disorders. New York: Raven Press, 1979:93-112. 